\title{
BMJ Open The utility of health belief model to explain self-protective behaviour against pneumoconiosis in Chinese underground coal miners: a cross- sectional study
}

\author{
Qiong Liu, ${ }^{1,2}$ Wanli Chen, ${ }^{1}$ Renjie Qi, ${ }^{1}$ Yang Geng, ${ }^{1}$ Ya Liu, ${ }^{1}$ Ying Zhou, ${ }^{1}$ \\ Chenggang Zhang, ${ }^{3}$ Xian Wang, ${ }^{3}$ Jiwei Wang, ${ }^{1}$ Jinming $\mathrm{Yu}^{1}$
}

To cite: Liu Q, Chen W, Qi R, et al. The utility of health belief model to explain selfprotective behaviour against pneumoconiosis in Chinese underground coal miners: a cross-sectional study. BMJ Open 2019;9:e026772. doi:10.1136/ bmjopen-2018-026772

- Prepublication history for this paper is available online. To view these files, please visit the journal online (http://dx.doi org/10.1136/bmjopen-2018026772).

\section{QL and WC contributed equally.}

Received 20 September 2018 Revised 13 March 2019 Accepted 14 March 2019

\section{Check for updates}

(C) Author(s) (or their employer(s)) 2019. Re-use permitted under CC BY-NC. No commercial re-use. See rights and permissions. Published by BMJ.

${ }^{1}$ Key Laboratory of Health Technology Assessment of Ministry of health, School of Public Health, Fudan University, Shanghai, China

${ }^{2}$ School of Basic Medical Sciences, Fudan University, Shanghai, China

${ }^{3}$ Shanghai Xuhui Centre for Disease Control and Prevention, Shanghai, China

\section{Correspondence to} Dr Chenggang Zhang; zhangcg76@sina.com and Dr Jiwei Wang;

jiweiwang@fudan.edu.cn

\section{ABSTRACT}

Objectives Coal workers' pneumoconiosis is caused by exposure to respirable coal mine dust. The self-protection of underground coal miners (UCM) plays an irreplaceable role against this threat. The purpose of this study was to evaluate the predictors of self-protective behaviour (SPB) in Chinese UCM based on the health belief model (HBM). Methods A cross-sectional study was conducted among 341 UCM in January 2016 in Pingdingshan City, Henan Province, People's Republic of China. Data was collected using a self-reported questionnaire, which included questions on sociodemographic characteristics, HBM variables and SPB. An exploratory factor analysis of the principal components with varimax rotation was carried out on the HBM-related items. Pearson's correlation and multiple linear regression analysis were used to assess the relationship between sociodemographic characteristics, $\mathrm{HBM}$ variables and SPB.

Results Multiple regression analysis demonstrated the monthly income $(B=0.403, p=0.001)$, the internal cues to action $(B=0.380, p<0.001)$ and external cues to action ( $B=0.401, p<0.001)$ as the predictors of UCM's SPB, accounting for $24.8 \%$ of total variance ( $F=34.96$, $\mathrm{p}<0.001$ ), while the cognition variables of HBM were not significantly associated with SPB.

Conclusion The results suggested that both internal and external cues to action were powerful predictors for SPB. These findings highlight that further efforts are required to provide the UCM with periodic health check-up reports and promote the active role of doctors and family members in miners' decision-making to simulate them for better SPB. Ethics approval All data collection procedures received ethical approval from the Ethics Committee of Xuhui District Centre for Disease Control and Prevention (XHHEC-2016-7).

\section{INTRODUCTION}

China is the largest coal producer and consumer country in the world, occupying $46.1 \%$ and $50.6 \%$ of total production and consumption respectively according to the British Petroleum (BP) Statistical Review of

\section{Strengths and limitations of this study}

- The health belief model was applied in this study to explain the Chinese underground coal miners (UCM's) self-protective behaviour (SPB).

- All participants in the present study are from the same coal mine company, which limited the generalisability of the findings to the whole Chinese UCM.

- The smoking history and respiratory symptoms were not investigated in this study. However, the association between smoking and lower levels of attitudes about SPB should not be ignored. Moreover, the respiratory symptoms might be impacted by SPB

- This study did not investigate the education levels of participants. However, the education levels might also be associated with UCM's SPB, even though the education levels of UCM in China are generally low.

- Underground mining work hours, which was associated with income and dust exposure, need a detailed survey and more attention in future studies.

World Energy 2017. ${ }^{1}$ Due to the development of mining technology and the adjustment of energy supply structure, a lot of town/privateowned collieries have been closed or amalgamated, and it is estimated that the number of underground coal miners (UCM) in China decreased to 4.7 million in 2010 to 2014 from 6 million in $2004 .^{2}$ The prolonged inhalation of mine dust could contribute to severe lung disease, including coal workers' pneumoconiosis (CWP), which is one of the common occupational diseases in China, ${ }^{3}{ }^{4}$ and severely impacts the health and quality of life of UCM.

According to incomplete statistics, China mainland has reported 770000 cases of occupational pneumoconiosis up to 2014, and CWP accounted for about $55 \%$. Moreover, the incidence of occupational disease in China nowadays is still comparatively high. ${ }^{6}$ In 2016 , 
31789 new occupational diseases were reported in China, including 27992 new cases of occupational pneumoconiosis. Among them, $95.49 \%$ of the cases were coal workers' pneumoconiosis and silicosis, which included 16658 cases and 10072 cases, respectively. ${ }^{7}$ The current situation is far from achieving the target of eliminating pneumoconiosis in 2030 put forward by the WHO and International Labour Organisation. ${ }^{8}$

In China, the survival of patients with pneumoconiosis is not sufficient. ${ }^{910}$ One survival analysis of CWP patients in a state-owned mine in the east of China from 1963 to 2014 showed that the average survival was 12.1 years after diagnosis of CWP and the average death age was 57.4 years. ${ }^{11}$ Another analysis of patients in Changsha from 1956 to 2010 pointed out the life expectancy was 60.12 years. ${ }^{12}$ Both results are significantly lower than the 76.1 years of the Chinese average life expectancy reported by the WHO in $2015 .{ }^{13}$ The healthcare costs and the lost economical or societal contribution resulting from premature death or disability attributed to the CWP were huge. ${ }^{14}$

To date, there is no published research demonstrating that effective treatment could reverse the process of CWP. ${ }^{15} 16$ The most important measure of pneumoconiosis is prevention. ${ }^{17}{ }^{18}$ Ventilation and humidification operations are essential preventive measures to reduce dust density. Exposures to respirable coal mine dust (free Silicon dioxide $\left.\left(\mathrm{SiO}_{2}\right)<10 \%\right)$ should be limited to $2.5 \mathrm{mg} /$ $\mathrm{m}^{3}$ as a time-weighted average concentration for up to an 8 hour working day during a 40 hours working week in China. ${ }^{19}$ The state administration of work safety of China stipulates that the coal mines should monitor the density of respiratory dust once a month. It also demands that coal mines should organise an occupational health assessment or examination with a subsequent management report for each miner every 2 years.

In addition, personal dust masks also provide significant protection to coal miners. ${ }^{20}$ One study in China indicated that the utilisation rate of personal protective equipment was only $72.6 \%$, and only $43 \%$ of the respondents reported that they wear the dust mask each time as required. ${ }^{21}$ Therefore, improving patients' awareness of preventing CWP and stimulating self-protective behaviour (SPB) is greatly urgent. The coal enterprises are paying more attention to the provision and training of protective equipment to the UCM. ${ }^{22}{ }^{23}$ However, there is still a lack of understanding of UCM's SPB beliefs.

Previous studies showed that some theory-based educational programmes that applied cognitive frameworks could have a positive effect on behavioural adherence. ${ }^{24}{ }^{25}$ The health belief model (HBM) was developed in the 1950s and has been widely drawn on to explain alterations in health-related behaviours. ${ }^{26}$ This model is comprised of several components: perceived susceptibility, perceived severity, perceived benefits, perceived barriers and cues to action. Perceived susceptibility describes a person's subjective perception of the risk of developing a health problem. Perceived severity refers to an individual's subjective assessment of the severity of a health problem and its potential consequences. Perceived benefits refer to an individual's perception of the effectiveness of various actions to reduce the threat of diseases. Perceived barriers refer to an individual's perception of the obstacles to behaviour change. Cues to action are internal or external events that determine a person's readiness for action and trigger the decision-making process. ${ }^{27}$ Based on the HBM theory, to adopt a preventive action, a person must know the seriousness of health problems, recognise benefits of preventive behaviour, feel lack of serious barriers and perceive the impact from the events, people or things that move them to change their behaviour. HBM has been employed in a variety of public health settings over the years.

In this cross-sectional study, the HBM was utilised as the theoretical framework to design the questionnaire. The purpose of this study was to evaluate the predictors of SPB in Chinese UCM based on HBM. The findings may help the coal mine manager and health professionals to develop feasible interventions to improve adherence to $\mathrm{SPB}$ in Chinese UCM.

\section{METHODS \\ Participants}

This cross-sectional study was carried out among male underground coal miners from a state-owned coal mining enterprise in Pingdingshan city, Henan Province, China. Among the company's 4968 employees, 3074 underground coal miners are exposed to the dust, and they are divided into 46 working groups. We randomly selected six working groups with a total of 410 underground coal miners.

In January 2016, the self-reported questionnaires were distributed to 410 underground coal miners in their work fields, 41 refused either because of their work time limitation or poor literacy ability. The response rate was $90.0 \%$. Three hundred sixty-nine questionnaires were collected in the field with full data on measures for 279 questionnaires. There were 62 questionnaires with missing less than four questions and another 28 with more missing, which was determined as incomplete, as which field investigators were not able to check in limited time. Finally , 341 questionnaires were analysed. The valid rate of this survey was $92.4 \%$.

Before filling in the self-reported survey questionnaire, the participants would be informed of the study purpose, data collection methods and how to complete the questionnaire. They also were informed that their participation was completely anonymous and voluntary. Participants were informed about this research and that they have the right to withdraw from the study. Participants who were incapable of completing the questionnaire themselves were assisted by an investigator who read the questions one by one and recorded the answers. After the participants completed the surveys, the field investigators were responsible for checking 
the completeness of questionnaires, asking participants to fill the missing information. The research team rechecked questionnaires to decide whether questionnaires were complete before entering data into the database. All investigators in the field are the authors of this paper.

Written informed consent was obtained from each participant.

\section{Instruments}

\section{Sociodemographic characteristics}

The sociodemographic characteristics included age, gender, marital status, length of employment and monthly income.

\section{HBM variables}

In this study, we developed the items that assessed the components of the HBM, and 30 items were combined under five primary constructs: perceived susceptibility (four items), perceived severity (six items), perceived benefits (five items), perceived barriers (four items), cues to action (seven items) and self-protection behaviour (four items).

In order to facilitate respondents' responses to the items, all items were standardised to a 5-point Likert scale, ranging from 1 (strongly disagree) to 5 (strongly agree). Every subscale's mean was determined by dividing the total points of all the subscale items by the total number of items. Therefore, the mean score of the HBM model variables could range from 1 to 5 . The higher score indicates a greater level of belief and self-protective behaviours. Readers can request a questionnaire from the corresponding author.

\section{Statistical analysis}

EpiData Entry was used for data entry and documentation. The Statistical Package for the Social Sciences (SPSS V.22.0) was used for data manipulation and analysis. Summary statistics and frequency distributions were used to describe the sociodemographic characteristics of participants. To assess and confirm the underlying factor structure of the pre-designed HBM items, an exploratory factor analysis (EFA) of the principal components with varimax rotation was carried out on the HBM-related items. The following criteria were used in analysing and guiding the obtainment of the results. An eigenvalue $>1$ was used as a cut-off point to determine the applicability of the pre-designed factors of the HBM. Items with factor loading $>0.5$ and conceptual relevance were used as criteria for retaining in a factor. Items with loadings $>0.4$ on two or more factors were excluded. Pearson's correlation and multiple linear regression analysis were used to assess the relationship between sociodemographic characteristics, HBM variables and SPB.

\section{Patient and public involvement}

This study has no patient or public involvement.

\section{RESULTS}

\section{Sociodemographic characteristics of subjects}

The sociodemographic characteristics of participants in the present study are shown in table 1 . The 341 participants are all male, with an average age of 38.3 years and an average employment time of 13.2 years. A majority $(67.7 \%)$ of respondents earned less than 385 pounds per month.

\section{Exploratory factor analysis and descriptive statistics of HBM variables}

EFA yielded seven factors with eigenvalues $>1$ that accounted for $65.9 \%$ of total variance. Three items were deleted in light of the criteria mentioned above. The Kaiser-Meyer-Olkin measure (KMO value of 0.81 ) and Bartlett's test $\left(\chi^{2}=4169, \mathrm{p}<0.001\right)$ confirmed the adequacy for the EFA. One of the four questions focused on 'perceived susceptibility' was deleted for showing a factor loading $>0.4$ in another factor ('perceived severity') in the forepart analysis. Two of the seven items about 'cues to action' were cut-off, and the remaining five were divided into two different parts. Combined with the items' connotation, one part was thought to be the cues from self-review and the other from someone's suggestion. Finally, the seven factors were perceived susceptibility, perceived severity, perceived benefits, perceived barriers, internal cues,

Table 1 Sociodemographic characteristics of main study participants $(n=341)$

\begin{tabular}{ll}
\hline Characteristic & Summary statistics \\
\hline $\begin{array}{l}\text { Age (years) } \\
\text { Mean } \pm \text { SD }\end{array}$ & $38.3 \pm 7.9$ \\
\hline Range & 21 to 55 \\
\hline $\begin{array}{l}\text { Length of employment } \\
\text { Mean } \pm \text { SD }\end{array}$ & $13.2 \pm 9.7$ \\
\hline Range & 1 to 38 \\
\hline Monthly income (£), $\mathrm{n}(\%)$ & \\
\hline$\leq 275$ & $53(15.5)$ \\
\hline 275 to 330 & $48(14.1)$ \\
\hline 330 to 385 & $130(38.1)$ \\
\hline$>385$ & $96(28.2)$ \\
\hline Missing & $14(4.1)$ \\
\hline Marital status, $\mathrm{n}(\%)$ & \\
\hline Married & $304(89.1)$ \\
\hline Single & $23(6.7)$ \\
\hline Others & $10(3.0)$ \\
\hline Missing & $4(1.2)$ \\
\hline Registered permanent residence, $\mathrm{n}(\%)$ \\
\hline Rural area & $126(37.0)$ \\
\hline Urban area & $202(59.2)$ \\
\hline Missing & $13(3.8)$ \\
\hline
\end{tabular}


Table 2 Factor loading. Reliability coefficient. Mean and SD

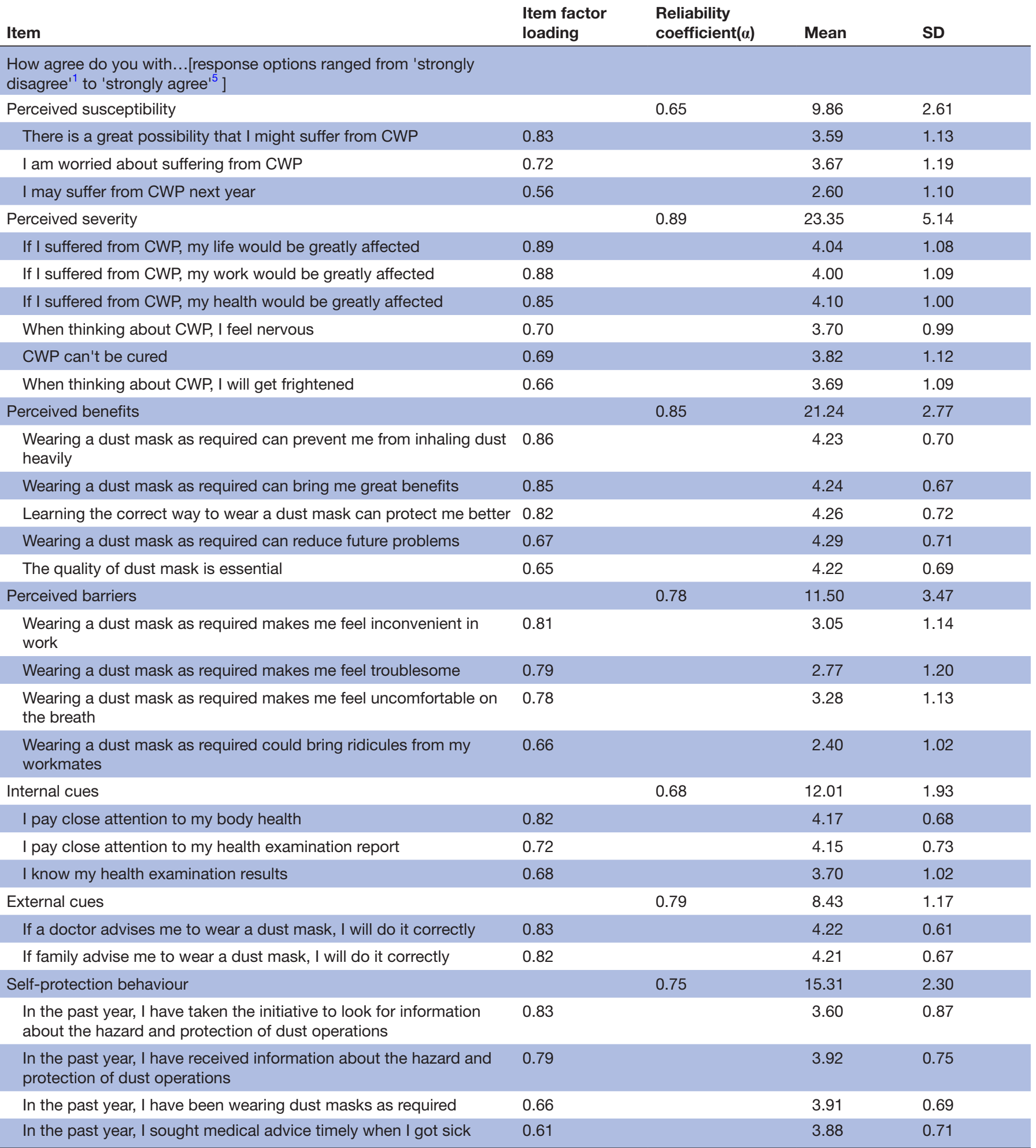

CWP, coal workers' pneumoconiosis.

external cues and self-protective behaviour. Factor scores were calculated by summing the subordinate items' scores. The factor loadings based on EFA, Cronbach's alpha, score mean and SD for these scales and items were presented in table 2.
Correlations between sociodemographic characteristics, HBM variables and SPB

The bivariate correlation for the study variables was shown in table 3. It was found that the SPB of UCM only had statistically significant positive correlations with 
Table 3 Bivariate correlation of sociodemographic characteristics, HBM variables and SPB

\begin{tabular}{|c|c|c|c|c|c|c|c|c|c|c|}
\hline & 1 & 2 & 3 & 4 & 5 & 6 & 7 & 8 & 9 & 10 \\
\hline 1. Age & 1 & & & & & & & & & \\
\hline $\begin{array}{l}\text { 2. Length of } \\
\text { employment }\end{array}$ & $0.845^{\star *}$ & 1 & & & & & & & & \\
\hline 3. Monthly income & $-0.254^{\star \star}$ & $-0.307^{\star *}$ & 1 & & & & & & & \\
\hline $\begin{array}{l}\text { 4. Perceived } \\
\text { susceptibility }\end{array}$ & -0.055 & 0.001 & -0.100 & 1 & & & & & & \\
\hline $\begin{array}{l}\text { 6. Perceived } \\
\text { benefits }\end{array}$ & -0.007 & 0.029 & 0.042 & $0.136^{\star}$ & $0.331^{\star *}$ & 1 & & & & \\
\hline $\begin{array}{l}\text { 7. Perceived } \\
\text { barriers }\end{array}$ & 0.034 & 0.043 & -0.092 & $0.107^{\star}$ & 0.072 & -0.035 & 1 & & & \\
\hline
\end{tabular}

All $P$ values are two-tailed.

${ }^{\star} \mathrm{p}<0.05 ;{ }^{* \star} \mathrm{p}<0.01$. HBM, health belief model; SPB, self-protective behaviour.

perceived benefits and cues in all HBM variables. The majority of cognition variables (perceived susceptibility, perceived severity and perceived barriers) had no significant correlations with SPB. In addition, there was a significant positive association between monthly income and $\mathrm{SPB}$, while monthly income was correlated with other sociodemographic characteristics (age and length of employment).

\section{Multiple linear regression analysis accounts for variance of SPB}

To explore the predictor variables of SPB, the main independent variables such as age, length of employment, monthly income and all HBM variables entered the regression model analysis. The results of this analysis are shown in table 4. Accordingly, monthly income, internal cues and external cues were significant predictors of SPB in UCM. The overall model significantly explained $24.8 \%$ of the variance in SPB $(\mathrm{F}=34.96, \mathrm{p}<0.001)$.

\section{DISCUSSION}

From the perspective of UCM, the present study evaluated predictors of SPB in Chinese UCM based on HBM. The results of multiple linear regression analysis indicated that the level of income, internal and external cues to action were significant predictors to SPB while other cognitive variables in the HBM were not.

Monthly income is significantly associated with SPB. The incomes of UCM in China mainly depend on downhole work hours. The longer downhole work time

\begin{tabular}{|c|c|c|c|c|c|c|c|}
\hline Variable & B & SE & $\boldsymbol{\beta}$ & $t$ & $p$ & $\mathbf{F}$ & $\mathbf{R}^{2}$ \\
\hline Constant & 6.015 & 1.600 & & 3.816 & 0.000 & \multirow[t]{8}{*}{34.96} & \multirow{8}{*}{$0.248^{\star \star \star}$} \\
\hline Length of employment & 0.007 & 0.023 & 0.032 & 0.330 & 0.742 & & \\
\hline Monthly income & 0.403 & 0.119 & 0.178 & 3.397 & 0.001 & & \\
\hline Perceived severity & -0.053 & 0.027 & -0.119 & -1.960 & 0.051 & & \\
\hline Perceived benefits & 0.059 & 0.045 & 0.071 & 1.312 & 0.191 & & \\
\hline Perceived barriers & -0.022 & 0.033 & -0.033 & -0.662 & 0.508 & & \\
\hline Internal cues & 0.380 & 0.065 & 0.316 & 5.805 & 0.000 & & \\
\hline External cues & 0.401 & 0.109 & 0.205 & 3.683 & 0.000 & & \\
\hline
\end{tabular}

${ }^{\star \star *} \mathrm{P}$ value $<0.001$ 
means a higher risk of CWP in UCM and the need for better SPB. Besides, more disposable personal income also provides support for their health management (eg, better medical experience, additional physical examination).

Cues to action represent internal and external forces that may drive behaviour change and were found to be the key predictors of miner's SPB in our study. Cues to action were divided into two parts based on the EFA and items' connotation. Internal cues represent the individual understanding of physical health status, through the focus on physical examination and the acquisition of results. This kind of understanding may arouse the miner's awareness of the current physical condition and thus take the initiative to implement self-protection. On the other hand, the requirements and reminders from doctors or family members, considered as external cues, also promote workers to protect themselves. As people often comply with doctors' advice, doctors could play critical roles in helping the UCM develop the SPB. Meanwhile, family members of UCM need to understand the occupational hazards of underground coal work and the importance of self-prevention. They are also responsible for reminding UCM to protect their safety and health. Nowadays, the UCM rarely receive regular education about the knowledge of self-protection against the CWP. $^{28}$ The external forces should play a more important role in this process. It implies that more efficient use of behavioural cues will help Chinese UCM attach importance to SPB.

The WHO recommends that all workers exposed to coal dust should undergo lifelong health surveillance. ${ }^{29}$ Implementing periodic medical examinations and providing timely feedback to UCM could make them aware of their health status and alert them about the potential risk of illness. The chest scanning may allow for CWP detection at an earlier stage and avoid further dust exposure. ${ }^{3}$ Although cognitive factors of HBM in this study did not promote better SPB, the education on perceived susceptibility, perceived severity, perceived benefits and perceived barriers for UCM should not be ignored.

This study also contains limitations that should be addressed. First, all participants in this study are from the same coal mine company, which limited the generalisability of the findings to the whole Chinese UCM. Second, this study did not investigate the education levels of participants. However, education levels may also be associated with UCM's SPB, even though the education levels of UCM in China are generally low. Third, this study did not investigate the smoking history of participants. However, the association between smoking and lower levels of attitudes about health-related behaviours should not be ignored. ${ }^{30}$ Moreover, the respiratory symptoms might be impacted by SPB. Finally, underground mining work hours, which was associated with income and dust exposure, were neglected in this study and needed precise survey in future studies.

\section{CONCLUSION}

This study advances the understanding of Chinese UCM's SPB by using a valid theoretical framework provided by HBM. The results suggested that both internal and external cues to action were powerful predictors for SPB. In order to simulate miners for better SPB, further efforts are needed to provide the UCM with periodic health check-up reports and promote the active role of doctors as well as family members in miners' decision-making.

Contributors QL supervised data collection, interpreted the data and drafted and revised the manuscript. WC interpreted the data, and drafted and revised the manuscript. $R Q, Y G, Y L$ and $Y Z$ supervised data collection. $C Z, X W$ and $\mathrm{JY}$ formulated the overarching research goals and aims. JW formulated the overarching research goals and aims, and drafted and revised the manuscript. The investigation was supported by coal mine management personnel, giving us great convenience.

Funding This research was funded by the Fudan University Students Winter Vacation Social Practice in 2016, Shanghai Public Health Key Discipline Plan (Nos. 15GWZK1001).

Disclaimer The results presented here are solely the responsibility of the authors and do not necessarily represent the views of the study funders.

Competing interests None declared.

Patient consent for publication Not required.

Ethics approval Xuhui District Centre for Disease Control and Prevention Research Ethics Committee (XHHEC-2016-7).

Provenance and peer review Not commissioned; externally peer reviewed.

Data sharing statement Data can be obtained from corresponding author Wang Jiwei (Email: jiweiwang@fudan.edu.cn).

Open access This is an open access article distributed in accordance with the Creative Commons Attribution Non Commercial (CC BY-NC 4.0) license, which permits others to distribute, remix, adapt, build upon this work non-commercially, and license their derivative works on different terms, provided the original work is properly cited, appropriate credit is given, any changes made indicated, and the use is non-commercial. See: http://creativecommons.org/licenses/by-nc/4.0/.

\section{REFERENCES}

1. BP Statistical Review of World Energy [Internet]. $2017 \mathrm{http}: / / \mathrm{www}$. bp.com/content/dam/bp/en/corporate/pdf/energy-economics/ statistical-review-2017/bp-statistical-review-of-world-energy-2017full-report.pdf (cited 17 Aug 2018).

2. Liu FD, Pan ZQ, Liu SL, et al. The estimation of the number of underground coal miners and normalization collective dose at present in China. Radiat Prot Dosimetry 2017;174:302-7.

3. Perret JL, Plush B, Lachapelle P, et al. Coal mine dust lung disease in the modern era. Respirology 2017;22:662-70.

4. Han L, Han R, Ji X, et al. Prevalence characteristics of Coal Workers' Pneumoconiosis (CWP) in a State-Owned Mine in Eastern China. Int J Environ Res Public Health 2015;12:7856-67.

5. Zhang CC, Li Y. Discussion on the status quo and strategy of pneumoconiosis prevention and treatment. World Latest Medicine Information 2016;16:122-3.

6. Occupational Health Risk Assessment [Internet]. 2015 http://niohp. chinacdc.cn/zyb/201611/P020161118395628433664.pdf

7. Chinese Occupational Disease Report [Internet] 2015-2016. 2017 http://niohp.chinacdc.cn/jbjcbg/201804/t20180404_162101.htm.

8. Galloway E. Elimination of Silicosis in the Americas [Internet]. 2007 http://www.who.int/occupational_health/publications/newsletter/ gohnet12e.pdf (cited 20 Aug 2018).

9. Cui JW, Ja H, Zhu L. Survival analysis of pneumoconiosis cases in Yueyang City from 1963 to 2014. Zhonghua Lao Dong Wei Sheng Zhi Ye Bing Za Zhi 2016;34:360-2.

10. Tang $\mathrm{H}$, Wang $\mathrm{Y}$, Chen $\mathrm{H}$, et al. [Case fatality rate in patients with pneumoconiosis in China: a meta-analysis]. Zhonghua Lao Dong Wei Sheng Zhi Ye Bing Za Zhi 2015;33:229-32. 
11. Han L, Gao Q, Yang J, et al. Survival Analysis of Coal Workers' Pneumoconiosis (CWP) Patients in a State-Owned Mine in the East of China from 1963 to 2014. Int J Environ Res Public Health 2017:14:489

12. Xue J, Chen L. [Survival analysis of patients with pneumoconiosis from 1956 to 2010 in Changsha]. Zhong Nan Da Xue Xue Bao Yi Xue Ban 2012;37:84-8.

13. World Health Organization. World Health Statistics 2016: Monitoring health for the SDGs Annex B: tables of health statistics by country, WHO region and globally [Internet]. $2016 \mathrm{http} / / / \mathrm{www} . \mathrm{who} . \mathrm{int} / \mathrm{gho} /$ publications/world_health_statistics/2016/Annex_B/en/

14. Zhang L, Zhu L, Zh L, et al. Analysis of disease burden and its influencing factors in hospitalized patients with coal worker's pneumoconiosis. Beijing Da Xue Xue Bao Yi Xue Ban 2014:46:226-31.

15. Blackley DJ, Halldin CN, Cummings KJ, et al. Lung transplantation is increasingly common among patients with coal workers' pneumoconiosis. Am J Ind Med 2016;59:175-7.

16. Petsonk EL, Rose C, Cohen R. Coal mine dust lung disease. New lessons from old exposure. Am J Respir Crit Care Med 2013;187:1178-85.

17. Vallyathan V, Landsittel DP, Petsonk EL, et al. The influence of dust standards on the prevalence and severity of coal worker's pneumoconiosis at autopsy in the United States of America. Arch Pathol Lab Med 2011;135:1550-6.

18. Yh X, Lu Y, Wang XL. Investigation on the effect of knowledge-based line mode on health education of pneumoconiosis hospitalized patients. Pract Prev Med 2015;22:1073-5.

19. National Occupational Health Standards of China [Internet]. 2018 http://www.nhfpc.gov.cn/ewebeditor/uploadfile/2018/07/ 20180727180633558.pdf (cited 17 Nov 2018).
20. Li H, Wang ML, Seixas N, et al. Respiratory protection: associated factors and effectiveness of respirator use among underground coal miners. Am J Ind Med 2002;42:55-62.

21. Fan HM, Cui W, Yuan JX, et al. Investigation and research on dust control status of coal enterprises. J Saf Sci Technol 2011;7:47-51.

22. Wang ZX, Qin RL, Yz L, et al. Occupational disease hazards and their protection status in 23 coal mining enterprises in China. J Environ Occup Med 2009;26:565-8.

23. Zhang JR. Analysis of occupational disease reports and personal protective equipment use of laborers in Hefei City from 1974 to 2006. Xian dai yu fang yi xue 2008;35:2223-5.

24. Simoni JM, Franks JC, Lehavot K, et al. Peer interventions to promote health: conceptual considerations. Am J Orthopsychiatry 2011;81:351-9.

25. Jeihooni AK, Hidarnia A, Kaveh MH, et al. Application of the health belief model and social cognitive theory for osteoporosis preventive nutritional behaviors in a sample of Iranian women. Iran J Nurs Midwifery Res 2016;21:131-41.

26. Rosenstock IM. Historical Origins of the Health Belief Model. Health Educ Monogr 1974;2:328-35.

27. Janz NK, Becker MH. The health belief model: a decade later. Health Educ Q 1984;11:1-47.

28. Bodenhamer AA. The Resurgence of Black Lung: A Critical Examination of Environmental IIIness in Central Appalachia. Raleigh, North Carolina: North Carolina State University, 2017.

29. Wagner GR. Screening and surveillance of workers exposed to mineral dust [Internet]. Geneva: World Health Organization, 1996. Available from. http://www.who.int/occupational_health/publications/ mineraldust/en/. (cited 18 Aug 2018)

30. Dawood OT, Rashan MA, Hassali MA, et al. Knowledge and perception about health risks of cigarette smoking among Iraq smokers. J Pharm Bioallied Sci 2016;8:146-51. 